\title{
DAS SEZESSIONSRECHT INNERSTAATLICHER RECHTSGEMEINSCHAFTEN
}

\author{
Von Dieter Blumenwitz
}

Das Recht einer Gemeinschaft, sich vom Gesamtverband zu lösen, gehört zu den umstrittensten Instituten der Staatsrechtstheorie und hat die gesamte Lehre der Staatenverbindung tiefgreifend beeinflußt.

\section{Einführung}

Das Sezessionsrecht der innerstaatlichen Rechtsgemeinschaft ist für die Dezentralisation der auswärtigen Gewalt von besonderer Bedeutung, da aus ihm der Hinweis auf eine zumindest latent vorhandene oder beibehaltene Völkerrechtssubjektivität der berechtigten Gemeinschaft entnommen wurde. Andererseits kann das Sezessionsrecht eines Gliedstaates oder eines assoziierten Staates den auf seine Integrität bedachten Gesamtverband zwingen, seine Außen- wie auch Innenpolitik mit den einzelnen Rechtsgemeinschaften so abzustimmen, daß es nicht zur rechtlich möglichen Sezession kommt. Auch die mit dem Gesamtverband abgeschlossenen völkerrechtlichen Verträge werden durch die Sezession eines Teiles des Vertragsgebietes berührt.

1. Die Untersuchung geht von dem weitgefaßten, staatstheoretisch neutralen Begriff der „innerstaatlichen Rechtsgemeinschaft" ${ }^{\prime 1}$ aus. Durch die Bezeichnung „innerstaatlich“ soll die Untersuchung auf Rechtsgemeinschaften beschränkt werden, die primär nicht völkerrechtsunmittelbar sind. Damit entfällt die Problematik des Austritts aus einer staatenbündisch strukturierten Gemeinschaft, obgleich sich auch hier Sezessionsprobleme ergeben können, wenn der Staatenbund seinen Mitgliedsstaaten - die geborene Völkerrechtssubjekte bleiben - den Austritt oder die Auflösung der Gemeinschaft verbietet ${ }^{2}$.

1 In einem ähnlich weiten Sinn werden in der anglo-amerikanischen Literatur die Begriffe "constituent members of a State", constitutional (political) subdivisions of a State" und "component entities of a constitutional subdivision or association" verwandt.

Die Bearbeiter und Berichterstatter der International Law Commission (ILC), die sich mit den einschlägigen Problemen zu befassen hatten, gingen bei ihren Uberlegungen nicht von dem in den klassischen Bundesstaaten entwickelten Gliedstaatsbegriff aus; vgl. hierzu insbesondere Castrén (Finnland) in YBILC 1962 , Bd. I, S. 193, und YBILC 1965, Bd. I, S. $23 \mathrm{ff}$

Sir Humpherey Waldock schlug in seinem ersten Bericht (YBILC 1962, Bd. II, S. $27 \mathrm{ff}$.) den über den Bereich der klassischen Bundesstaaten hinausreichenden Begriff "constituent States of a federation or union" (Art. $3 \int 2$ des Entwurfs 1962) vor. Insbesondere die niederländische Regierung wies in den Verhandlungen mehrfach auf die neu entstandenen Formen der Staatenassoziationen hin, die als "union of States" bezeichnet wurden und deren Glieder in den Kreis der möglichen Vertragssubjekte einbezogen werden sollten. Die endgültige Fassung der Draft Articles on the Law of Treaties spricht von „States membres of a federal union" (Art. 5 Abs. 2); während der erläuternde Kommentar der ILC zu Art. 5 mur den "federal State" anspricht, wird doch aus den Stellungnahmen der Kommissionsmitglieder ersichtlich, $\mathrm{da}$ der Begriff "federal union" weiter gefaßt ist als der herkömmliche Begriff des Bundesstaates und daß auch Assoziationen ohne vollausgebaute Föderalstruktur miterfaßt werden sollten, vgl. YBILC 1965, Bd. I, S. 246 und 256. Steinberger hält in seinen kritischen Anmerkungen zur Bestimmung allerdings zumindest eine Klarstellung für erforderlich, vgl. ZaöRV, Bd. 27 (1967), S. 428.

Es fällt auf, daß die ILC bei all ihren Versuchen, das Problem einzukreisen, an dem Begriff Staat („State ${ }^{\alpha}$ ) festhält; der Begriff "State“ wurde jedoch von Anfang an so weit gefaßt, daß jede Rechtsgemeinschaft von der karibischen Insel bis zum UN-Mitglied Ukraine darunterfällt; vgl. etwa den ersten Bericht von Fitzmaurice, YBILC 1956, Bd. II, S. $107 \mathrm{ff}$. Art. 3: „,State means an entity consisting of a people inhabiting a defined territory, under an organized system of government, and having the capacity to enter into international relations binding the entity as such, either directly or trough some other State".

Die Konvention über das Recht der Verträge vom 23. Mai 1969 (= Convention on the Law of Treaties, A/CONF. 39/27) - in ihrer nunmehr endgültigen Fassung - klammert die Problematik allerdings aus. Eine vor der 8. Sitzung des Plenums am 28. April 1969 in Wien unternommene diplomatische Aktion Kanadas führte zur Streichung von Art. 5 Abs. 2 der Draft Articles. Vgl. Verosta, Die UN-Vertragskonferenz 1968/69 und die Konvention, in: ZaöRV, Bd. 29 (1969), S. 654 ff. (675).

2 Vgl. hierzu W. Fischer, Das Austrittsrecht aus Staatenverbindungen, Diss. Zürich, 1957. 
Im Zusammenhang mit dem Sezessionsrecht interessieren im Folgenden nur die geschriebenen oder ungeschriebenen Normen, auf denen der Gesamtverband beruht, also nicht der revolutionäre und auch nicht der friedliche Austritt aus der Gemeinschaft, der mit der ursprünglichen Verfassung des Gesamtverbandes nicht in Einklang steht ${ }^{3}$.

2. Die Gebietskörperschaften, die sich kraft Verfassungsrechts vom Gesamtverband lösen können, treten bei einer rechtsvergleichenden Untersuchung der einzelnen Staatsverfassungen in sehr unterschiedlicher Form auf. Sie lassen sich in zwei Gruppen einordnen: die Gliedstaaten der sogenannten Bundesstaaten und die assoziierten Staaten.

a) Den Gliedstaaten ist gemeinsam ein gewisses $M a ß$ an Autonomie, die sich darin äußert, daß die jeweilige Bundesverfassung den sie mittragenden Rechtsgemeinschaften Zuständigkeitsbereiche zur selbstverantwortlichen Regelung zuweist (wobei sich die Selbstverantwortlichkeit auch darin zeigt, wie die Normen erlassen werden); weiter ist charakteristisch eine gewisse Bestandsgarantie der Gliedstaaten und eine mehr oder weniger große direkte Beteiligung der Gliedstaaten an der Bildung des Gesamtwillens ${ }^{4}$.

b) Im Gegensatz zur bundesstaatlichen Ordnung kann die verfassungsrechtliche Verbindung von Staaten sich auch auf der Basis der Ungleichheit vollziehen ${ }^{5}$. Dieser Staatenstaat gilt als Schöpfung des Feudalismus als überlebt ${ }^{6}$, gewinnt aber in der besonderen Form der staatsrechtlichen Assoziation - auch Binnenassoziation genannt $^{7}$ - wieder an Bedeutung. Der Grund hierfür liegt in Art. 73 b der UN-

3 Die Abgrenzung kann in Einzelfällen Schwierigkeiten bereiten. Dies zeigt der Austritt Singapurs aus der Föderation Malaysia im Jahre 1965. Die Annual Survey of Commenwealth Law (ASCL) 1966, S. 59, hat hier die Ansicht vertreten, "Singapore was excluded from the Federation under duress, but in accordance

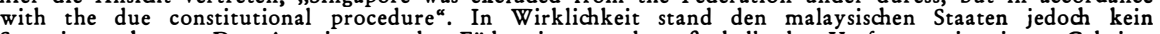
Sezessionsrecht zu. Der Austritt aus der Föderation wurde außerhalb der Verfassung in einem Geheimabkommen zwischen der Regierung von Malaysia und Singapur vom 7. August 1965 vereinbart (vgl. Keesing, 1965, 20.891 f.). Im Constitution of Malaysia (Singapore Amendment) Act 1965 (No 53 of 1965 ) und Malaysia (Amendment) Act 1965 (No 54 of 1965) beschloß das malaysische Parlament die mit dem Austritt Singapurs notwendig werdenden Änderungen und regelte Fragen der Staatsangehörigkeit, Staatensukzession und gemeinsamer Versorgungseinrichtungen (z. B. Wasserversorgung für Singapur). In der State of Singapore Government Gazette Extraordinary vom 9. August 1965, S. 2184 wurde der Text des "Independence of Singapore Agreement 1965" veröffentlicht; weiter wurde veröffentlicht eine vom Prime Minister Malaysias unterzeichnete Erklärung, in der die Unabhängigkeit Singapurs anerkannt wurde. Im Ergebnis handelte es sich deshalb um eine Sezession im Einvernehmen mit dem Gesamtstaat, die sich jedoch außerhalb der Verfassung des Gesamtstaates vollzog.

$4 \mathrm{Im}$ Grunde ist es jedoch keiner der bisher entwickelten Theorien vom Bundesstaat gelungen, eine für alle bundesstaatlichen (oder so bezeichneten) Ordnungen allgemein gültige Regel aufzustellen; es gibt kaum ein von der Theorie für maßgeblich erklärtes Kriterium, das nicht durch das positive Recht einer oder mehrerer als „bundesstaatlich“ angesehener Verfassungen widerlegt würde; zu den Unterschieden in der Erscheinungsform der Bundesstaaten siehe auch Ermacora, Uber das Wesen des österreichischen Bundesstaates in Theorie und Praxis, in: JBl. 79 (1957), S. 573. Zu der Vielfalt der theoretischen Deutungen, Hesse, Der unitarische Bundesstaat, Karlsruhe 1962, S. 55 ff., Scheuner, DƠV 1962, S. 641 f., H. Krüger, Allgemeine Staatslehre, Stuttgart 1964, S. $162 \mathrm{ff}$.

5 Vgl. Berber, Völkerrecht I, München 1960, S. 143; Kunz, Staatenverbindungen in: Stier-Somlo's Handbuch des Völkerrechts, Bd. II, Abt. 4, Stuttgart 1929, S. 520 ff.; Nawiasky, Staatenverbindungen in: Strupp: Schlochauer, Wörterbuch des Völkerrechts, Bd. III, Berlin 1962, S. 314. Allerdings bereitet der Begriff der Gleichheit bzw. der Ungleichheit mitunter Schwierigkeiten, da das Prinzip der Gleichheit von einigen Autoren auch dann als eingehalten angesehen wird, wenn die Minderberechtigung der Rechtsgemeinschaft durch ihre Minderverpflichtung als kompensiert gelten soll (so etwa im Falle Puerto Ricos, das im USamerikanischen Kongreß nicht vertreten ist, aber auch keine Bundessteuern zu entrichten hat; vgl. Fahrni, Die Assoziation von Staaten mit anderen Staaten, Zürich 1967, S. $30 \mathrm{f}$., 78 und $84 \mathrm{ff}$.); im Grunde handelt es sich hier jedoch um politische Motive, die den Status der Ungleichheit rechtfertigen sollen, vgl. Th. Fleiner. Die Kleinstaaten in den Staatenverbindungen des 20. Jahrhunderts, Zürich 1966, S. 47.

Die Abgrenzung zum Bundesstaat mit hegemonialer Vormachtstellung eines Gliedstaates läßt sich rechtlich nur durch das formale Kriterium der Mitwirkung der Gliedstaaten an der Bildung des Gesamtwillens erreichen. In der neueren Staatsrechtslehre wird zwar im Zweikammersystem kein notwendiges Kriterium des Bundesstaates erblickt (so z. B. Usteri, Theorie des Bundesstaates, Zürich 1953, S. 262); es handelt sich hier jedoch um Ansichten, die den Föderalismus nicht durch die Verfassungsurkunde, sondern durch die konkrete Ưbung nachweisen wollen - sich also nicht der normativen, sondern der soziologischen Methode bedienen. 6 Vgl. Menzel, Völkerrecht, München 1962, S. 115.

7 So Kloss, Die Assoziation, in: Vereinte Nationen 1963, S. $168 \mathrm{ff}$. 
Charta, der die Verwaltungsmächte gewisser „non-self-governing territories ${ }^{\text {* }}$ verpflichtet, die Fähigkeit der Bewohner ihrer abhängigen Gebiete zur Selbstregierung zu entwickeln. Wie sich aus der die Treuhandsgebiete betreffenden Vorschrift des Art. 73 b ergibt, unterscheidet die Satzung zwischen Selbstregierung (self-government) und Unabhängigkeit (independence). Die Generalversammlung hat in einer Reihe von Entschließungen diese Begriffe präzisiert ${ }^{9}$. Die in der EntschlieBung vom 27. November 1953 enthaltene Faktorenliste ${ }^{10}$ unterscheidet zwischen Unabhängigkeit, anderen Systemen der Selbstregierung und freier Assoziation; eine übersichtliche Neufassung dieser Einteilung enthalten die 12 Selbstbestimmungsgrundsätze von 196011, die zwischen Unabhängigkeit, freier Assoziation und Integration unterscheiden. Für den Bereich der vorliegenden Untersuchung kommt dem Umstand Bedeutung zu, daß die unter dem Leitgedanken „Selbstbestimmungsrecht der Völker" betriebene Dekolonialisierung nicht unbedingt die Entstehung neuer unabhängiger Staaten zum Ziel hat, sondern auch die Integration und die freie staatsrechtliche Assoziation der kolonialen Rechtsgemeinschaft zuläßt ${ }^{12}$. Die Integration einer kolonialen Rechtsgemeinschaft in das Mutterland oder in einem anderen unabhängigen Staat wirft hierbei keine besonderen staatsrechtlichen Probleme auf ${ }^{13}$. Bei der freien Assoziation kann es sich sowohl um eine völkerrechtliche als auch um eine staatsrechtliche Verbindung handeln; erstere erscheint als eine Art Nachfolgeinstitution des Protektorats ${ }^{14}$ und interessiert

$8 \mathrm{Um}$ welche Gebiete es sich hierbei im einzelnen handelt, läßt die UN-Charta offen; wie sich aus den Kap. XII und XIII ergibt, zählen die UN-Treuhandsgebiete, die einer Sonderregelung unterstell wurden, nicht dazu. Die UNO hat es ihren Mitgliedstaaten zunächst überlassen, die von ihnen verwalteten abhängigen Gebiete selbst zu benennen: 8 Kolonialmächte übersandten dem Generalsekretär die nach Art. 73e UN-Charta fälligen Jahresberichte, behielten es sich jedoch vor, die Liste der informationspflichtigen Gebiete in Zukunft zu vergrößern, aber auch einzuschränken. Die Generalversammlung hat sich jedoch in der Folgezeit das Recht vorbehalten, "to decide whether a non-self-governing Territory has or has not attained a full measure of self-government as referred to in Chapter XI of the Charter". Vgl. dazu auch Toussaint, The Colonial Controversy in the United Nations, in Year Book of World Affairs, 1966, S. $170 \mathrm{ff}$. Der Versuch der belgischen UN-Delegation im Jahre 1952, auch nichtkoloniale Beziehungen in den Anwendungsbereich des Kap. XI der UN-Charta einzubeziehen, kann als gescheitert gelten, so daß etwa autoritär regierte Minderheiten nicht unter die Vorschrift fallen, vgl. Berber, Völkerrecht I, München 1960, S. 161, und Grundsatz I der Resolution 1541, Text: UNYB 1960, S. $509 \mathrm{f}$.

9 In der Literatur ist verschiedentlich die Ansicht vertreten worden, daß Selbstregierung und Unabhängigkeit gleichbedeutend seien (vgl. etwa Ross, Constitution of the United Nations, New York 1950, S. 185, und Verdross, Völkerrecht, 5. Aufl., Wien 1964, S. 191) oder daß „self-government “ Souveränität beinhalte (vgl. Singh, The Goal of Trusteeship Self-Government or Independence? in: Australian Outlook, 1961, S. $295 \mathrm{ff} ., 298$, und de Yturriaga, Non-self-governing Territories, in: The Year Book of World Affairs 1964, S. $178 \mathrm{ff} .$, 196).

10 Resolution 742 (VIII) Text: UNYB 1953, S. $526 \mathrm{ff}$; deutsche Ubersetzung in: Vereinte Nationen 1962, S. $93 \mathrm{f}$.

11 Resolution 1541 (XV) Text: UNYB 1960, S. 509 f.; deutsche Ubersetzung in: Vereinte Nationen 1962 , S. 94. Grundsatz VI bestimmt: „A non-self-governing territory can be said to have reached a full measure of self-government by:

a) Emergence as a souvereign independent State,

b) Free association with an independent State, or

c) Integration with an independent State.

Vgl. hierzu auch den am 1. Mai 1970 gebilligten Entwurf des Drafting Committee des Special Committee on Principles of International Law concerning Friendly Relations and Co-operation among States UNDoc. A/AC. 125/L. 86.

12 Bezügl. gewisser Einschränkungen durch Resolution 1541 vom 14. Dezember 1960, vgl. unten Fn. 28.

13 Die Integration beurteilt sich nach der Verfassung des aufnehmenden Staates und muß auf der Grundlage völliger Gleichheit erfolgen; der Integration hat eine diesbezügliche freie Entscheidung der Bevölkerung des betroffenen Gebiets vorauszugehen, vgl. Res. 742, Teil 3, und Res. 1541, Grundsätze VIII und IX, jeweils a. a. O.; Beispiele: Grönland (Res. 849, IX), Alaska und Hawaii (Res. 1469, XIV) als Integration in das Mutterland; die Vereinigung des ehemaligen britischen Treuhandgebiets Togo mit dem neu gegründeten Staat Ghana (Res. 1044, XI) als als Integration in einen unabhängigen dritten Staat; umstritten und von der UN-Generalversammlung nicht akzeptiert ist die nicht auf dem Grundsatz der Gleichheit der Rassen vollzogene Integration der portugiesischen Kolonien ins Mutterland, vgl. Kägi, Die rechtliche Entwicklung vom Kolonialregime zur nationalen Unabhängigkeit, in: Europa und der Kolonialismus 1962, S. $123 \mathrm{ff}$. (S. 156).

14 Vgl. Fahrni, a. a. O., S. $147 \mathrm{ff}$. und $167 \mathrm{f}$., und das Verhältnis von West-Samoa (Samoa i Sisifo) und Neuseeland auf Grund des 1962 geschlossenen Assoziationsvertrages, durch den sich Neuseeland bereit erklärt, West-Samoa auf dessen Wunsch von Fall zu Fall völkerrechtlich zu vertreten (hierzu auch Broderick, Associated Statehood - A new Form of Decolonisation, in: The International and Comparative Law Quarterly 1968, S. 403); West Samoa hat auch vorerst den Antrag auf UN-Mitgliedschaft zurückgestellt. Durch die völkerrechtliche Assoziation wird das durch die Staatenpraxis vergangener Jahre in Mißkredit gefallene Protektorat seiner ursprünglichen Bedeutung der freiwilligen Vertretung, die überwiegend im Interesse des Vertretenen liegt, wieder zugeführt. 
im Rahmen der innerstaatlichen Rechtsgemeinschaften nicht weiter; bei der letzteren Assoziationsform treten echte innerstaatliche Rechtsgemeinschaften auf, die im Unterschied zur vollintegrierten kolonialen Rechtsgemeinschaft nicht gleichberechtigt sind mit der übrigen Bevölkerung des Staates, mit dem das Assoziationsverhältnis eingegangen wird. Wenn in der Staatenpraxis die staatsrechtliche Assoziation neben der Integration Bestand hat, so deshalb, weil die Minderberechtigung meist auch eine Minderverpflichtung bewirkt ${ }^{15}$, keine völlige Assimilation der Rechtsgemeinschaft eintritt ${ }^{16}$ und ihr unter Umständen durch die Gewährung eines Sezessionsrechtes der Weg zur Eigenstaatlichkeit nicht versperrt wird ${ }^{17}$.

\section{Die positiv-rechtliche Regelung des Sezessionsrechts in den Verfassungen der Gegenwart}

\section{Das Sezessionsrecht der assoziierten Staaten}

Zweifellos spielt das Sezessionsrecht bei den assoziierten Staaten eine größere Rolle als in den gemeinhin als bundesstaatlich bezeichneten Verfassungen. So konnten alle Mitgliedstaaten der französischen Gemeinschaft nach der Verfassung von 1958 durch Beschluß ihrer gesetzgebenden Versammlungen, der durch Volksabstimmung zu bestätigen war, die Gemeinschaft verlassen und unabhängig werden ${ }^{18}$. Hieraus darf jedoch keinesfalls geschlossen werden, daß allen assoziierten Staaten das Recht zusteht, sich vom Oberstaat zu lösen, da ja die Assoziation sowohl als Vorstufe der vollen Unabhängigkeit als auch der vollen Assimilation konzipiert sein kann. So steht Puerto Rico, Surinam und den Niederländischen Antillen und auch den Färöern kein Sezessionsrecht zu, obwohl in den beiden letztgenannten Fällen die niederländische und die dänische Regierung durchblicken

15 So insbesondere steuerliche Vorteile (vgl. Puerto Rico); auch im übrigen scheinen finanzielle Gesichtspunkte bei der Frage der Assoziation eine gewichtige Rolle zu spielen, vgl. The Times vom 23. August 1967, S. 2, Spalte 1 und 2.

$16 \mathrm{Vgl}$. Chaumont, La décolonisation aux Nations Unis, in: Tiers-Monde, Bd. I (1961), S. $49 \mathrm{f}$. Wie die Verbindung Eritreas mit Äthiopien zeigt, kann allerdings auch eine staatsrechtliche Assoziation im weiteren Verlauf zu einer Assimilation der Rechtsgemeinschaft führen: Eritrea akzeptierte am 5. Mai 1952 einen von UN-Experten ausgearbeiteten Verfassungsentwurf, der die Eingliederung der ehemals italienischen Kolonie als demokratisch regiertes autonomes Gebiet in das Kaiserreich Äthiopien vorsah; die Bundesakte wurde am 11. September 1952 von Äthiopien ratifiziert; in den Jahren nach 1958 verzichtete das Parlament von Eritrea mehr und mehr auf seine Autonomie, bis am 14. November 1962 die letzten Spuren der Assoziation beseitigt worden waren. Vgl. Einzelheiten bei Dagafou, Die völkerrechtliche Lage Äthiopiens nach 1941, Diss. Bonn 1961, S. 145 ff.; Greenfield, Ethiopia, London 1965, S. 303 ff.; Schiller, Eritrea: Constitution and Federation with Ethiopia, in: The American Journal of Comparative Law 1953, S. $375 \mathrm{ff}$.

17 Bei diesen staatsrechtlich assoziierten Gebieten handelt es sich im einzelnen um 1. Puerto Rico (in seiner Stellung zu den Vereinigten Staaten), 2. Surinam und die Niederländischen Antillen (in ihrer Beziehung zu dem Königreich der Niederlande), 3. die Cook-Inseln (in ihrem Verhältnis zu Neuseeland) und schließlich 4. um die Leeward- und Windward-Inseln (in ihrer Verbindung zu Großbritannien).

Weitere Beispiele der staatsrechtlichen Assoziation waren die Verbindung Eritreas mit Äthiopien von 1952-1962 (vgl. dazu Fn. 16) und die französische Gemeinschaft nach Titel XII der Verfassung vom 4. Oktober 1958: Die Verbindung der Republik Frankreich mit den assoziierten Mitgliedstaaten war bis zur Verfassungsreform des Jahres 1960 grundsätzlich staatsrechtlicher Natur; mit Erlangung der Unabhängigkeit hörten die Staaten auf, Mitglieder der Communauté zu sein; 1960 wurde der Art. 84 der Verfassung dahin geändert, daß ein Mitgliedstaat auf dem Vertragswege unabhängig werden kann, ohne seine Mitgliedschaft in der Communauté zu verlieren (vgl. La Révision constitutionnelle relative à la Communauté, in: Revue juridique et politique d'outre-mer 1960, S. 457); vgl. Einzelheiten bei Weinbuch, Entkolonialisierung und föderales Prinzip im Spiegel der Französischen Gemeinschaft, Berlin 1967, S. 111 ff. Fahrni, a. a. O., S. 135 ff.; Luchaire, Droit d'outre-mer, Paris 1959; Gandolfi, Les accords de coopération en matière politique étrangère entre la France et les nouveaux Etats Africains et Malgache, in: Revue juridique et politique d'outre-mer 1963, S. $202 \mathrm{ff}$.; Pinto, Die Communauté in der Französischen Verfassung von 1959, in: Schweizer Monatshefte 1959, S. $814 \mathrm{ff}$.

Aber auch außerhalb des von Art. 73 UN-Charta kontrollierten Raums treten staatsrechtliche Assoziationen auf, wie etwa die besonderen rechtlichen Beziehungen der Färöer zu Dänemark zeigen; vgl. Einzelheiten bei Veiter, Die Autonomie der Färöer, in: ZaöRV, Bd. 20 (1959/60), S. 243 ff.; Fahrni, a. a. O., S. 112 f. 18 Vgl. Pinto, a. a. O., S. 817; Freudenberg, Französische Gemeinschaft, in: Strupp-Schlochauer, a. a. O., Bd. I, S. 559. 
ließen, daß sie sich Sezessionswünschen nicht verschließen würden ${ }^{\mathbf{1 9}} \mathbf{2 0}$ und so ein friedlicher Weg zur Eigenstaatlichkeit offen bleibt.

Gesetzlich besonders geregelt wurde das Sezessionsrecht für die Leeward- und Windward-Inseln wie auch für die Cook Islands.

a) Die Cook Islands

Am 4. August 1965 wurden die bis dahin von Neuseeland als Kolonie verwalteten Cook Islands ein "self-governing State in free association with New Zealand“21. Das Inselparlament kann nunmehr alle Gesetze „for the peace, order and good government of the Cook Islands" selbst erlassen ${ }^{22}$ und auch die Verfassung einseitig ändern ${ }^{23}$. Das neuseeländische Parlament kann für die Inseln nur Gesetze erlassen mit „advice and consent" der dortigen Legislative Assembly ${ }^{24}$.

$\mathrm{Da}$ dem Parlament der Cook Islands im vollen Umfang das Recht zusteht, die Verfassung von $1965 \mathrm{zu}$ ändern, können auch die Verfassungsbestimmungen aufgehoben werden, auf denen die Assoziation mit Neuseeland beruht. Damit ist eine Sezession der Inseln durch einen mit Zweidrittelmehrheit gefaßten Parlamentsbeschluß möglich, der allerdings noch der Zustimmung von zwei Dritteln der Bevölkerung in einem K.eferendum bedarf ${ }^{25}$.

b) Die Leeward- und Windward-Islands

Nach dem Scheitern der 1957 gegründeten karibischen Föderation ${ }^{26}$, die 1962 die Unabhängigkeit erlangen sollte, sah sich Großbritannien gezwungen, in bezug auf die kleineren Inselbesitzungen im karibischen Raum neue staats- und völkerrechtliche Wege einzuschlagen. Es handelt sich im einzelnen um sechs Inselterritorien

19 Nach van Helsdingen soll nur deshalb das Sezessionsrecht der überseeischen Gebiete nicht in die Verfassung aufgenommen worden sein, da von vornherein Úbereinstimmung darüber bestanden habe, daß kein Land des Königreichs gegen seinen Willen im Reichsverband zurückgehalten werden kann (la charta du Royaume des Pays-Bas, in: Revue juridique et politique de l'Union Française 1956, S. 671); allerdings muß dem Austritt der überseeischen Gebiete erst eine Verfassungsänderung vorangehen, die in erster Linie der Zustimmung des europäischen Landesteils bedarf. Vgl. Einzelheiten bei van Panhuys, Nederlands Tijdschrift voor Internationaal Recht 1958, S. $17 \mathrm{f}$. In den Vorverhandlungen zum Statut des Königreichs der Niederlande vom 29. Dezember 1954 hatte vor allem Surinam ein Sezessionsrecht gefordert; der niederländische Minister für die überseeischen Territorien (Kernkamp) sicherte inter alia zu, daß die Gemeinschaft nur auf der freien Verbundenschaft („vrijwillige verbondenheit ${ }^{\prime}$ ) der Reichsteile aufgebaut werden sollte und daß auf das Selbstbestimmungsrecht der Territorien in der Präambel der Statuts Bezug genommen werden sollte; vgl. das sog. New Yorker Memorandum vom 5. Nov. 1952 und Memorie van Aatwoord, Rijksbegroting 1953, Kap. XIII B, S. 2. Schließlich wurde das Selbstbestimmungsrecht („het zelfwoord, Rijksbegroting 1953, Kap. XIII B, S. 2. Schließlich wurde das Selbstbestimmungsrecht ("het zelf-
beschikkingsrecht") wegen seiner Unbestimmtheit nicht in das Statut aufgenommen, vgl. Beratungen der zweiten Kammer, 1952-1953, S. 504.

20 Das geltende Autonomiegesetz von 1948 kann von den Färöer nicht einseitig geändert werden. Dänemark will sich jedoch ernsthaften Unabhängigkeitsbestrebungen nicht widersetzen, vgl. Nachweise bei Fahrni, a. a. O., S. 113, Anm. 202.

$21 \mathrm{Vgl}$. Report of the Department of Island Territories vom 31. März 1967, S. 5, und die Res. der Legislative Assembly der Cook Islands vom 27. Juli 1965 (Text: Broderick, a. a. O., S. 390). Vorangegangen war eine unter Mitwirkung von UN-Beobachtern abgehaltene Volksabstimmung, durch die sich die Bevölkerung für die völlige innere Selbstregierung bei gleichzeitiger Beibehaltung der Beziehungen zu Neuseeland entschied; auf der Grundlage des Volksentscheids erging im November 1964 der Cook Islands Constitution Act 1964 (Text: New Zealand Statutes, 1964, Bd. I, No. 69, S. 457) und der Cook Islands Constitution Amendment Act 1965 (Text: ibid. No. 70, S. 492).

22 Section 39; die Inselgesetze sind der extra-territorial application ${ }^{\alpha}$ fähig und stehen nicht unter dem Vorbehalt des Colonial Laws Validity Act; damit entfällt bei der Gesetzgebung die teilweise Mediatisierung durch die britische Krone, wie wir sie z. B. bei den australischen Gliedstaaten noch vorfinden (vgl. O'Connell, International Law, Bd. I, New York, London, 1965, S. 404 f.). Die Krone ist durch einen High Commissioner vertreten, der aber zugleich auch die Neuseeländische Regierung auf den Inseln vertritt (Section 3).

23 Section 41: normalerweise genügt 2/3 Mehrheit; bei Änderungen, die die neuseeländische Verantwortlichkeit für die Führung der Außen- und Verteidigungspolitik wie die Beendigung des Assoziationsverhältnisses zum Gegenstand haben, wird zusätzlich noch die Zustimmung der Bevölkerung ( $2 / s$ Mehrheit) in einem Referendum gefordert.

24 Außerhalb der Sitzungsperiode des Parlaments erteilt der High Commissioner auf Empfehlung des InselKabinetts die Zustimmung (Section 46).

25 Vgl. hierzu auch UN Monthly Chronicle, 1965, Nr. 8, S. 27 ff.; Commonwealth Survey, 1966, S. 983; External Affairs Review, 1965, Nr. 4, S. 5, und Nr. 8, S. 4, und oben Fn. 23.

26 Zur Föderation vgl. Wheare, Die Bundesstaaten im Britischen Commonwealth, in: Schweizer Monatshefte 1959, S. 745; ihr Mißerfolg wurde durch den Austritt der beiden größten Inseln Jamaica und TrinidadTobago besiedelt. Neue Föderationsversuche scheiterten an der Haltung der Inseln Grenada und Antigua die wiederum die größte der verbliebenen Inseln - nämlich Barbados - veranlaßte, den Weg in die Unabhängigkeit allein zu gehen. Vgl. auch Thomas, Constitutional Theory and Practice in the West Indies, in: JöR, Bd. 15 (1966), S. $683 \mathrm{ff}$. 
der Leeward- und Windward-Inseln ${ }^{27}$, die wegen ihrer isolierten Lage, ihrer einseitigen wirtschaftlichen Struktur und finanzieller Abhängigkeit keine lebensfähigen Einheiten bilden.

Durch den britischen „West Indies Act 1967“28 wurde eine Lösung gefunden, die die Inseln bei weitgehender innerer Autonomie frei mit dem Mutterland assoziiert. Die Inseln sind autonom, soweit es sich nicht um Angelegenheiten der Staatsangehörigkeit, der Verteidigung und Thronfolge und um auswärtige Beziehungen von überregionaler Bedeutung handelt ${ }^{29}$. Das Assoziationsverhältnis kann von beiden Seiten mit gewissen Einschränkungen beseitigt werden ${ }^{30}$.

Das den sechs Inselterritorien der Leeward- und Windwardinseln durch den britischen West Indies Act 1967 eingeräumte Recht, die Assoziation mit dem britischen Mutterland frei $z u$ beenden, hat in dem für Kolonialfragen zuständigen UNSpecial Committee eine große Rolle gespielt ${ }^{31}$. Das einzuschlagende Verfahren ist in der Schedule 2 zum West Indies Act näher geregelt; im einzelnen wird Gesetzesform verlangt, wobei zwischen erster und zweiter Lesung 90 Tage verstreichen müssen; das Gesetz muß sodann nach dritter Lesung mit 2/3 Mehrheit beschlossen, vom Governor bestätigt und von der jeweiligen Bevölkerung mit $2 / 3$ Mehrheit gebilligt werden ${ }^{32}$. Das Referendum kann entfallen, wenn der assoziierte Inselstaat den Zusammenschluß mit einem unabhängigen Commonwealth-Staat im karibischen Raum plant, der die Verantwortung für die Verteidigung und die auswärtigen Angelegenheiten der Insel übernimmt ${ }^{33}$. Bislang hat keiner der Inselstaaten von seinem Sezessionsrecht Gebrauch gemacht. Die Sezessionsversuche der Insel Anguilla seit Juli $1968^{34}$ fallen nicht unter den West Indies Act, da diese Insel kein selbständiges Inselterritorium bildet, sondern seit 1873 mit den Inseln St. Kitts (St. Christopher) und Nevis eine Verwaltungseinheit umfaßt. Bis 1969 handelte es sich um eine interne Angelegenheit der Regierung in St. Kitts. Erst im Frühjahr 1969 griff Großbritannien durch die Entsendung von Fallschirmjägern ein, nachdem die Insel ihre Unabhängigkeit auch von Großbritannien erklärte, Vermittlungen scheiterten und eine Übernahme der Staatsgewalt durch Gangstergruppen befürchtet wurde ${ }^{35}$. Der Versuch einer revolutionären Loslösung ist damit vorerst gescheitert.

27 Antigua, St. Kitts-Nevis-Anguilla, Dominica, St. Lucia, St. Vincent und Grenada.

28 1967, c. 4; in Kraft getreten am 27. Februar 1967 für Antigua und St. Kitts-Nevis-Anguilla, am 3. März 1967 für Dominica und St. Lucia, am 3. März 1970 für Grenada, am 5. März 1967 für St. Vincent. Anders als im Falle der Cook Islands ging der durch den West Indies Act erfolgten Assoziierung kein Volksentscheid voraus; das zuständige Spezial Committee der Vereinten Nationen sieht deshalb in der Lösung keine Verwirklichung des Selbstbestimmungsrechts und will die Territorien - trotz des ihnen eingeräumten Sezessionsrechtes - weiterhin als Kolonien betrachten, vgl. United Nations Document A/AC 109/SR 491, 492, S. $6 \mathrm{f}$.

29 Section 2; allerdings bleibt der britischen Regierung vorbehalten zu entscheiden, in welchen Kompetenzbereich eine bestimmte Materie fällt, wobei dann auch das Verfassungsrecht der Inseln der britischen Zuständigkeit zu weichen hat; letztere kann weit ausgedehnt werden, da unter defence $^{\alpha}$ nicht nur die Verteidigung der Insel, sondern alle Maßnahmen verstanden werden müssen, die mit der Verteidigung des gesamten Empire in Zusammenhang stehen. Im übrigen sind die Inselterritorien bei ihrer Gesetzgebung frei (so findet insbesondere der Colonial Laws Validity Act 1865 keine Anwendung).

30 Die britische Regierung kann die Verbindung jederzeit kündigen (durch „Order in Council ${ }^{\star}$ ), hält sich jedoch an eine 6-Monats-Frist gebunden, vgl. Broderick, a. a. O., S. 386.

31 Vgl. United Nations Documents A/AC 109/SR 494, S. 11, und United Nations Monthly Chronicle für März und April 1967.

$32 \int 2$; sofern die Verfassung des jeweiligen Inselstaats ein Zweikammersystem vorsieht und die Kammern verschiedene Auffassungen haben, entscheidet bezüglich der Differenzen das Referendum, $\$ 3$.

$33 § 4$ (2) (a)

$34 \mathrm{Da}$ sich die Insel von der Regierung in St. Kitts wirtschaftlich vernachlässigt fühlte (vgl. dazu The Times vom 7. November 1967 , S. 5, Spalte 7) und ihre Wünsche nach lokaler Selbstverwaltung enttäuscht sah, wurden im Juli 1967 die 17 Mann starken Polizeikräfte auf der Insel entwaffnet. Großbritannien lehnte zunächst eine Intervention ab, worauf sich die Regierung in St. Kitts an die Commonwealth-Staaten im karibischen Raum wandte; der von diesen Staaten erarbeitete Kompromiß (Barbados Agreement vom August 1967) wurde von der Bevölkerung Anguillas abgelehnt, vgl. The Times, 21. August 1967, S. 4, Spalte 8, und ASCL 1968 (1969), S. $786 \mathrm{f}$.

35 Vgl. Bericht über die Aktion, die weltweites Aufsehen erregte, in: SZ Nr. 68 vom 20. März 1969 , S. 3. 
Am 30. März 1969 unterzeichnete der Sonderbeauftragte Großbritanniens Lord Caradon mit Vertretern der Insel Anguilla einen vorläufigen Freundschafts- und Kooperationsplan ${ }^{36}$, der die Insel unter direkte Oberhoheit der britischen Krone stellt; die englischen Truppen bleiben für unbestimmte Zeit auf der Insel, die nicht mehr unter die Oberhoheit von St. Kitts zurückkehren muß. Sowohl der von der britischen Regierung eingesetzte Kommissar, Anthony Lee, als auch der Präsident der Insel, Webster, wurden in ihren Ämtern bestätigt.

Die vorläufige Einigung läßt offen, ob nunmehr der West Indies Act, 1967, unmittelbar auf Anguilla Anwendung finden soll; dies hätte zur Folge, daß auch dieser Insel - unabhängig von St. Kitts und Nevis - ein Sezessionsrecht zustünde. Allem Anschein nach wurden durch den Freundschafts- und Kooperationsplan noch nicht alle Probleme endgültig gelöst ${ }^{37}$.

\section{Das Sezessionsrecht der Gliedstaaten von Bundesstaaten}

Im Bereich der bundesstaatlichen Ordnungen ist das Sezessionsrecht innerstaatlicher Rechtsgemeinschaften in der sowjetrussischen, der jugoslawischen und der burmesischen Verfassung geregelt.

a) Das Sezessionsrecht der Unionsrepubliken der UdSSR

Die Union der Sozialistischen Sow jetrepubliken (UdSSR) ist am 30. Dezember 1922 durch Vertrag zwischen der Russischen Sozialistischen Föderativen Sowjetrepublik (RSFSR), der Ukrainischen, der Transkaukasischen und der Weißrussischen Sozialistischen Sowjetrepublik (SSR) entstanden ${ }^{38}$. Ob es sich bei dem Vertrag vom 30. Dezember 1922 um eine staatsrechtlich zu qualifizierende vorläufige Verfassung eines Einheitsstaates ${ }^{39}$ oder um einen völkerrechtlichen Vertrag ${ }^{40}$ handelt, ist streitig und hängt von der Würdigung des vorangegangenen revolutionären $\mathrm{Ge}-$ schehens $\mathrm{ab}^{41}$.

Dem russischen Selbstverständnis entspricht die Auffassung vom stufenweisen $\mathrm{Zu}$ sammenschluß freier Staaten ${ }^{42}$, die vom formaljuristischen Standpunkt akzeptiert werden kann. Die erste Verfassung der UdSSR vom 31. Januar 1924 hielt an dem Prinzip der Föderation formell „souveräner“ Republiken fest, räumte der

36 Vgl. hierzu SZ Nr. 78 vom 1. April 1969, S. 1.

37 Präsident Webster warf Großbritannien bereits wenige Tage nach der Einigung vor, die getroffene Vereinbarung gebrochen zu haben, und strebte erneut UN-Verhandlungen an; vgl. SZ Nr. 84 vom 8 . April 1969 S. 2; zu Plänen, die Insel mit der UNO zu assoziieren, vgl. ASCL 1968 (1969), S. $786 \mathrm{f}$

38 Stalin (Werke, Bd. 4, S. 85), der für Nationalitätenfragen zuständige Mann, forderte ursprünglich die Angliederung aller Sow jetrepubliken unter Gewährung von administrativer Autonomie an die RSFSR, doch konnte sich Lenins Unionsgedanke durchsetzen - nicht zuletzt, um den nach der Oktoberrevolution entstandenen "bourgeoisen" Nationalstaaten den Zusammenschluß schmackhafter zu machen. Der Vertragsentwurf wurde in den einzelnen Sowjetrepubliken besprochen, von ihren Delegierten auf dem I. Sowjetkongreß der UdSSR unterzeichnet und vom Kongreß einstimmig gebilligt. Text Istoriia sovjetskoi konstitutsii (v dokumentakh) 1917-1956, Moskau 1957, S. $394 \mathrm{ff}$. Diese Dokumentensammlung enthält konstitutsii (v dokumentakh) 1917-1956, Moskau 1957, S. $394 \mathrm{ff}$. Diese Dokumentensamml
auch alle weiteren für die verfassungsrechtliche Entwicklung der UdSSR wichtigen Unterlagen.

39 So allem Anschein nach Bilinsky, Die Entwicklung des sowjetischen Föderalismus, in: Jahrbuch für Ostrecht 1962/II, S. 24.

40 So Halajczuk, Das Sezessionsrecht - Art. 17 der Verfassung der UdSSR, in: Jahrbuch für Ostrecht 1968/I, S. $126 \mathrm{f}$; ders. The Soviet Ukraine as a subject of international law, in: The Annals of the Ukrainian Academy 1961/2, S. $182 \mathrm{ff}$. mit Hinweisen.

41 Vgl. hierzu Pipes, The Formation of the Soviet Union, 2. Aufl. Cambridge, Mass. 1964; Markus, L'Ukraine Soviétique dans les relations internationales 1918-1923. Etude historique et pratique, Paris 1959.

42 Die wohl als offiziell anzusprechende Lehre unterscheidet beim Aufbau der UdSSR drei Zeitabschnitte: die Periode der militärischen Bündnisse ( $v$ vojennyj sojus ${ }^{\alpha}$ ), die der wirtschaftlich-diplomatischen Bündnisse und die der Bildung der Union („sojus ${ }^{\alpha}$ ). Allerdings wird im neueren Schrifttum mitunter die Auffassung vertreten, daß die Sowjetrepubliken zur Zeit des Kriegskommunismus nur Verwaltungsgebiete der RSFSR vertreten, daß die Sowjetrepubliken zur Zeit
waren, vgl. hierzu Bilinsky, a. a. O., S. 21. 
RSFSR jedoch eine unüberwindbare Hegemonialstellung ein ${ }^{43}$. Trotz der mit der Einführung des ersten Fünfjahresplanes (1928) einherschreitenden Zentralisierung bestätigte die Stalinverfassung vom 5. Dezember 1936 den föderativen Staatsauf$\mathrm{bau}^{44}$, der zumindest der äußeren Struktur nach in vielen Aspekten geradezu vorbildlich der "bourgeoisen" bundesstaatlichen Ordnung entspricht ${ }^{45}$ und - bei Einbeziehung des verfassungsändernden Gesetzes vom 1. Februar 1944 - eine außerordentlich große Beteiligung der Gliedstaaten an den auswärtigen Angelegenheiten vorsieht ${ }^{46}$.

In dem am 30. Dezember 1922 in Moskau geschlossenen Vertrag behielten sich die Ukraine, Weißrußland und Transkaukasien den jederzeitigen Austritt aus der Union vor; diese Vertragsbestimmung wurde als Sezessionsrecht der Unionsrepubliken in die erste Verfassung aus dem Jahre 1924 (Art. 4) und auch wieder in die zweite, noch heute geltende Verfassung der UdSSR von 1936 (Art. 17) übernommen; ebenso erscheint das Sezessionsrecht in den einzelnen Verfassungen der Unionsrepubliken ${ }^{47}$.

Nach der Verfassung des Jahres 1924 war das Sezessionsrecht ein unveräußerliches Recht, konnte also nur mit Zustimmung der Signatarstaaten des Moskauer Vertrages verfassungsrechtlich beseitigt werden (Art. 6) ${ }^{48}$. Nach dem Wortlaut der Verfassung des Jahres 1936 gibt es keine unveräußerlichen Rechte der Unionsrepubliken mehr; in bezug auf die Anderung des in Art. 17 enthaltenen Sezessionsrechts genügt der in jeder Kammer mit Zweidrittelmehrheit gefaßte Beschluß des Obersten Sowjets (Art. 146), so daß es der Zustimmung einer jeden Unionsrepublik nicht bedarf. Trotzdem geht eine wohl als herrschend zu bezeichnende sowjetische Lehre davon aus, daß Art. 146 speziell auf Art. 17 keine Anwendung finden könne, da das Sezessionsrecht nicht in der Verfassung, sondern im freien

43 Oberstes Organ der UdSSR war nach dem Vertrag vom 30. Dezember 1922 der Sowjetkongreß, dessen Zentralvollzugskomitee zwischen den Sitzungen die Staatsgewalt ausübte; die Gleichheit der Unionsrepubliken sollte nunmehr durch ein Zweikammersystem (Unionsrat und Nationalitätenrat) garantiert werden, wobei namentlich die Repräsentanten der Ukraine forderten, daß keine Republik mit mehr als $2 / 5$ der Stimmen im Nationalitätenrat vertreten sein dürfe. Die Forderung Stalins, nicht nur die als ${ }^{2 / 5}$ der Stimmen im Nationalitätenrat vertreten sein dürfe. Die Forderung Stalins, nicht nur die RSFSR zu 64 Stimmen gegenüber nur 20 Stimmen der übrigen Republiken (nach Art. 15 besaß jede Unionsrepublik und autonome Republik 5, jedes autonome Gebiet einen Vertreter im Nationalitätenrat).

44 Text: Maurach, Handbuch der Sowjetverfassung, München 1955, Peaslee, Constitutions of Nations, 2. Aufl., Bd. 3, The Hague 1956, S. $485 \mathrm{ff}$.

45 Die Unionsrepubliken besitzen das Recht auf Vertretung in den folgenden Unionsorganen; Nationalitätenrat (durch selbständige Vertreter), Oberster Sowjet (durch einen stellvertretenden Vorsitzenden) Ministerrat (durch die Vorsitzenden ihrer Ministerräte), Oberstes Gericht (durch die Vorsitzenden ihrer Obersten Gerichte); Nachweise bei Bloembergen, The Union Republics: How much Autonomy?, in: Problems of Communism 1967, Heft 5, S. 30. Die Unionsrepubliken besitzen weiter Verfassungsautonomie, Gebietshoheit, Bestandsgarantie, Gesetzes- und Verwaltungskompetenz, soweit die Union die Angelegenheit nicht regelt. Die Unionsrepubliken können ihre Staatsangehörigkeit regeln und eigene Streitkräfte unterhalten. Hinzuzufügen ist allerdings, daß es kaum eine Verfassungsbestimmung mit materiellem Gehalt gibt, die in der Verfassungswirklichkeit nicht mehrfach gebrochen worden wäre; dies zeigt die für jede innerstaatliche Rechtsgemeinschaft besonders wichtige Bestands- und Gebietsgarantie (Art. 18 der Verfassung) sehr anschaulich: Ohne Zustimmung der betroffenen SSR wurde die karelische Landenge (Karelo-Finnische Unionsrepublik) in das Gebiet Leningrad der RSFSR eingegliedert; die Moldauische Unionsrepublik wurde praktisch durch Gesetz des Zentralstaates aus Teilen der Ukraine geschaffen. Vgl. Nachweise bei Maurach, a. a. O., Erl. zu Art. 18.

Die staatsrechtliche Qualifikation der UdSSR schwankt deshalb zwischen Staatenbund und Einheitsstaat. Auf die staatenbündischen Elemente wird immer wieder in der sowjetischen Literatur verwiesen, vgl. etwa Nedbailo und Vasilenko, Die Unionsrepubliken als Subjekte des Völkerrechts, in: Sovetskii yezhegodnik mezhdunarodnovo prava (Moskau 1965), S. $90 \mathrm{ff}$. Kritische Würigung bei Belz. Die Idee des Föderalismus in der Verfassung der UdSSR von 1936, maschinenschriftliche Diss. Göttingen 1962; ders., Das mus in der Verfassung der UdSSR von 1936, maschinenschriftliche Diss. Gottingen 1962; ders., Das The Government and Politics of the Soviet Union, New York 1965, S. $144 \mathrm{f}$;; Bloembergen, The Union Republics: How much Autonomy? a. a. O., S. $27 \mathrm{ff}$; ; siehe auch unten Fn. 76.

46 Art. 18a der Verfassung (VVS Nr. 8/1944).

47 Z. B. Art. 14 der ukrainischen, Art. 15 der weißrussischen Verfassung; die Verfassung der RSFSR enthält keine derartige Bestimmung.

48 Halajczuk (a. a. O., S. 126) spricht in diesem Zusammenhang vom Sezessionsrecht als einer ins innerstaatliche Verfassungsrecht inkorporierten völkerrechtlichen Norm. 
Zusammenschluß der Sowjetrepubliken begründet sei ${ }^{49}$. Die Stalin-Verfassung beseitigte Art. 20 der ersten Bundesverfassung, der an der rechtlichen Existenz des Sezessionsrechts einige Zweifel hatte aufkommen lassen; diese Bestimmung gab nämlich dem zentralen Exekutivkomitee der UdSSR die Möglichkeit, die Entscheidungen der Versammlungen der Sowjets der Unionsrepubliken und deren Exekutivkomitees aufzuheben; formal-juristisch hätte auf diese Weise auch der Beschluß einer Unionsrepublik, sich von der UdSSR zu lösen, ausgeräumt werden können ${ }^{50}$.

Die mit dem Sezessionsrecht zusammenhängenden Probleme bestehen in erster Linie nicht in der formal-juristischen Konstruktion, sondern in seiner Praktikabilität und Durchsetzbarkeit, da der Widerspruch gegen die Auffassung der herrschenden Staatspartei, daß keine Unionsrepublik die Sezession wünsche ${ }^{51}$, als Hochverrat bestraft und als Vergehen gegen die Geschichte betrachtet wird ${ }^{52}$.

b) Das Sezessionsrecht der jugoslawischen Republiken

Die sozialistische Föderative Republik Jugoslawien ist nach dem zweiten Weltkrieg durch die Verfassung vom 31. Januar 1946 entstanden ${ }^{53}$. Die besondere Bedeutung der Gliedstaaten wird durch das verfassungsändernde Gesetz von 1953 unterstrichen, das Jugoslawien als „sozialistischen demokratischen Bundesstaat souveräner und gleichberechtigter Völker" bezeichnet.

Nach der sehr umfangreichen Präambel ${ }^{54}$ zur derzeitigen jugoslawischen Verfassung vom 7. April 1963 haben sich die Völker Jugoslawiens „ausgehend von dem Recht eines jeden Volkes auf Selbstbestimmung einschließlich des Rechtes auf Loslösung ... zu einer Bundesrepublik freier und gleichberechtigter Völker und Nationalitäten vereinigt ...."

Obgleich der Gründung der jugoslawischen Föderation nicht wie in Rußland ein völkerrechtlicher Vertrag vorangegangen ist, erscheint die Normierung eines Sezessionsrechtes nicht nur als leere Kopie der UdSSR-Verfassung, sondern auch als Ausdruck der Interessengegensätze in dem Vielvölkergebiet ${ }^{55}$. Durch die Wiederholung des Sezessionsrechtes in der neuen Verfassung ist auch die zwischenzeitlich

49 So erst kürzlich wieder Zlatopolskij (Die UdSSR - Ein Bundesstaat, Moskau 1967, S. 260 - russisch): „Das Recht der sowjetischen Republiken zur Sezession kann durch die sowjetische Staatsgewalt nicht aufgehoben, abgeändert oder eingeschränkt werden. Dieses unveräußerliche Recht der Sowjetrepubliken ist mit ihrem freiwilligen Zusammenschluß ('obiedinienie') entstanden“ (zit. nach Halajczuk a. a. O., S. 127).

$50 \mathrm{Vgl}$. dazu etwa Eliaschew, Grundzüge der sowjetischen Verfassung, Heidelberg 1925; Mirkine-Guétzéwich, Théorie générale de l'Etat soviétique, Paris 1928, und Kunz, Staatenverbindungen, a. a. O., S. 588 ff.

51 So schon Stalin in seinem Kommentar vom 25. November 1936 zu Art. 17; Stalin hat hieraus jedoch nicht die Folgerung gezogen, daß das Sezessionsrecht obsolet sei (\#. . . Es ist offenkundig, daß es keine einzige Sowjetrepublik gibt, die die Loslösung von der UdSSR wünscht; aber man kann daraus nicht schließen, daß wir in der Verfassung das Recht der Republiken, sich frei von der UdSSR zu trennen, nicht etablieren sollten“. Zit. nach Halajczuk, a. a. O., S. 133); Stalin präzisierte vielmehr das Sezessionsrecht durch seine berühmten drei Bedingungen (Randlage der Republik, Majorität einer Nationalität in der Republik und eine gewisse Mindestbevölkerungszahl von ca. einer Million).

52 Vgl. dazu Maurach, a. a. O., S. 101, 106, 185; ders., Vierzig Jahre Nationalitätenrecht in der UdSSR (Vortrag vom 27. Juli 1957 vor dem Institut zur Erforschung der Sowjetunion), München 1957, S. 12 f.; Goodman, The Soviet Design for a World State, 3. Aufl. New York, S. 307. So wurde in der großen Säuberung, die dem Erlaß der Verfassung von 1936 folgte, der frühere Präsident des zentralen Exekutivkomitees der Uzbekischen Sowjetrepublik beschuldigt, die Loslösung der genannten Republik organisiert zu haben; Maurach, a. a. O., verweist auf den Bucharin-Rykow-Prozeß (1938), der die versuchte Loslösung der Ukraine, Weißrußlands, Georgiens, Armeniens und Aserbaidschans von der UdSSR zum Gegenstand hatte.

53 Die jugoslawische Staatsrechtslehre legt bei der Darstellung der historischen Entwicklung Wert auf die Feststellung, daß die Föderation von unten nach oben aufgebaut wurde, also nicht durch Gesetz des Einheitsstaates entstand; insoweit werden die ersten formellen Verfassungsakte in den Beschlüssen der II. Tagung des Antifaschistischen Volksbefreiungsrates vom 29. November 1943 gesehen, die Jugoslawien bereits als Bundesstaat von sechs Republiken konzipierten, vgl. Krbek, Die Verfassung der Sozialistischen Föderativen Republik Jugoslawien, in: JöR 1964, S. 244.

54 Vgl. Ziff. IX der Präambel: „Dieser Teil der Verfassung bildet - indem er die grundlegenden Prinzipien der sozialistischen Gesellschaft und ihres Fortschrittes zum Ausdruck bringt - auch die Grundlage für die Auslegung der Verfassung und der Gesetze, sowie für das Wirken aller und jedes einzelnen."

$55 \mathrm{Nadh}$ Peselj (Contemporary Croatia in the Yugoslaw Federation: its constitutional and socio-economic Position, in: Journal of Croatian Studies 1961, S. $101 \mathrm{f}$.) soll der frühere Generalsekretär der kroatischen Kommunistischen Partei, Andrija Hebrang, für Kroatien sogar denselben Status gefordert haben, wie ihn die Ukraine in der UdSSR besitzt. 
vertretene Auffassung widerlegt worden, die jugoslawischen Völker hätten durch ihren Zusammenschluß ihr Recht auf Loslösung von dem kommunistischen Staat verbraucht ${ }^{56}$. Trotz verschiedentlicher Spannungen unter den Völkern Jugoslawiens ${ }^{57}$ ist es jedoch auch nach 1963 zu keiner Ausübung des Sezessionsrechtes gekommen; die Verfassung stellt hierfür auch kein besonderes Verfahren zur Verfügung; die in der Präambel programmatisch erwähnten "Völker" tauchen im eigentlichen Text der Verfassung nicht mehr auf; Träger der verfassungsrechtlichen Rechte und Pflichten sind hier die als „sozialistische, demokratische Staatsgemeinschaften" bezeichneten Republiken und die autonomen Provinzen. Schon dadurch könnte die Ausübung des Sezessionsrechts in die unmittelbare Nähe eines konterrevolutionären Aktes gerückt werden.

c) Das Sezessionsrecht der burmesischen Minderheiten

Im Jahre 1947 sahen sich Großbritannien und rivalisierende Truppen in den sog. "Frontier Areas" und "Ministerial Burma“ mit dem Problem konfrontiert, aus diesem Vielvölkergebiet einen einigermaßen einheitlichen Staat zu formen ${ }^{58}$. Der in Form der Verfassung vom 24. September 1947 erzielte Kompromiß stellt einen der interessantesten verfassungsrechtlichen Versuche dar, die englische, jugoslawische, kanadische und indische Verfassungstradition miteinander zu vereinen ${ }^{59}$. Burma löste sein Minoritätenproblem durch einen partiell bundesstaatlichen Staatsaufbau; der als „Burma Proper“ bezeichnete Rumpfstaat bildet mit den in vier autonomen Staaten zusammengefaßten Minoritäten die Union of $\mathrm{Burma}^{60}$. Die föderalistische Struktur ist nur unvollkommen, da die bundesstaatlichen Organe aus Gründen der Kostenersparnis nicht voll ausgebaut sind; die Staaten haben im Chamber of Deputies und im Chamber of Nationalities feste Sitze. Die nach der festgesetzten Quote in die beiden Kammern des Unionsparlaments entsandten Mitglieder bilden zugleich als State Council das legislative Organ des betreffenden Staates.

Das mit der Überprüfung der Möglichkeit einer Staatsbildung im burmesischen Raum betraute „Frontier Areas Enquiry Committee“ berichtete 1947 der verfassungsgebenden Versammlung, daß die maßgeblichen Vertreter dieser Region einer Föderation mit Burma zustimmten, aber gleichzeitig ein Sezessionsrecht wünschten. Die Beratungen ergaben, daß das Sezessionsrecht eines Gliedstaates in bundesstaatlichen Verfassungen selten sei, dieses also besonders geregelt und eingeschränkt werden müsse ${ }^{61}$.

56 Vgl. Snuderl, Ustavne Pravo Federitivne Ljudske Republike Jugoslavije, Ljubljana 1956, Bd. I, S. 252 ff.; hierzu kritisch Peselj, a. a. O., S. 108.

57 So sind insbesondere anläßlich der 25. Jahrfeier der Gründung der jugoslawischen Föderation im November 1968 separatistische Tendenzen in dem albanischen Bevölkerungsteil im Sïdwesten des Staates erkennbar geworden (vgl. SZ vom 2. 1. 1969, S. 2).

58 Vgl. dazu das im Januar 1947 in London unterzeichnete Aung San - Attlee Agreement (veröffentlicht in London als command paper by His Majesty's Stationery Office: "Conclusions reached in the conversation between His Majesty's Government and the Delegation from the Executive Council of the Governor of Burma ${ }^{a}$ ), das dem entstehenden burmesischen Staat die Unabhängigkeit garantierte. Ein weiterer Schritt zur burmesischen Union war die im Februar 1947 mit der Anti-Fascist Peoples Freedom League abgehaltene Panglong-Konferenz, die den Grundstein zur burmesischen Verfassung legte, vgl. den kurzen Uberblick bei U Myint Soe, The Constitutional Development in Burma, in: JöR 1962, S. $366 \mathrm{ff}$.

59 Vgl. Maung Maung, Burma's Constitution, Den Haag 1959, S. 83 ff.; U Myint Soe, a. a. O., S. 369.

60 Nach Section 222 der Verfassung besteht die Union of Burma aus den "States" und "all the territories of the Union of Burma not forming part of any State"; die "States" waren ursprünglich der Shan-Staat, der Kachin-Staat und der Karenni-Staat (Section 5, 6, 7); der in der Verfassung vorgesehene Karen-Staat (Section 180) entstand erst nach revolutionären Auseinandersetzungen durch den Constitution Amendment Act 1951; nach der Bildung des Karen-Staates änderte der Karenni-Staat seine Bezeichnung zu Kayah-Staat. Die "Special Division of the Chins" (Section 196) besitzt nur gewisse Sonderrechte, jedoch keine Staatsqualität.

61 Vgl. Report, Part I, S. $28 \mathrm{ff}$.; die Einsetzung des „Frontier Areas Committee of Enquiry“ geht zurück auf das in London im Januar 1947 unterzeichnete Aung San - Attlee Agreement a. a. O.; $\$ 8$ sah vor die nearly unification of the Frontier Areas and Ministerial Burma with the free consent of the inhabitants of those areas". 
Das Sezessionsrecht wird in Kapitel X der Verfassung geregelt; jeder Staat hat das Recht, sich von der Union zu lösen, sofern durch die Verfassung oder durch Act of Parliament nichts anderes bestimmt wird (Sec. 201). Eine Sonderregelung enthält die Verfassung im Hinblick auf den Kachin-Staat ${ }^{62}$. Die Lehre räumt weiter dem 1951 nach einer Revolution neu gegründeten Karen-Staat das Sezessionsrecht nicht ein, da er in dem Constitution Amendment Act, 1951, nicht ausdrücklich erwähnt wurde ${ }^{63}$. Somit steht das Recht zur freien Lösung der mit Burma eingegangenen staatsrechtlichen Beziehungen nur dem Shan-Staat und dem Karenni-Staat (seit 1951 Kayah-Staat genannt) zu.

Nach Sec. 201 kann das Sezessionsrecht erst nach zehnjährigem Bestehen der burmesischen Union (also seit dem 4. Januar 1958) ausgeübt werden. Das Verfahren wird in Sec. 203-205 geregelt; der Staatsrat des sezessionsberechtigten Staates muß sich mit Zweidrittelmehrheit seiner gesetzlichen Stimmen für die Loslösung aussprechen; das Staatsoberhaupt notifiziert den burmesischen Staatspräsidenten, der ein Referendum zur Úberprüfung der Entscheidung des Staatsrates anordnet; die mit der Abhaltung des Referendums betraute Kommission setzt sich zu gleichen Teilen aus Vertretern der Union und des betroffenen Staates zusammen.

\section{Die völker- und staatsrechtliche Würdigung des Sezessionsrechts}

1. Verschiedentlich ist in der Staatsrechtslehre die Auffassung vertreten worden, daß den Gliedstaaten einer bundesstaatlichen Ordnung auch dann ein Sezessionsrecht zustehen könne, wenn dieses nicht ausdrücklich in der Verfassungsurkunde erwähnt sei. Schlüssig ist diese Meinung nur bei Bundesstaaten, die durch völkerrechtlichen Vertrag ihrer vormals unabhängigen Glieder entstanden sind. Weiter muß noch die Fiktion hinzutreten, daß durch den den Staatenverband begründenden völkerrechtlichen Vertrag die Völkerrechtssubjektivität der Abschlußstaaten nicht aufgehoben, sondern nur eingeschränkt wird. Auf dieser Grundlage baut Calhoun seine Theorie vom Federal Government auf, die er in der verfassungsmäßigen Ordnung der Vereinigten Staaten in der ersten Hälfte des 19. Jahrhunderts verkörpert sieht ${ }^{64}$. Das „Federal Government“ beruht ausschließlich

auf dem souveränen Willen der Mitgliedsstaaten, die die Befugnisse der Gemeinschaftsgewalt regeln und jederzeit die Union verlassen können, wenn sie glauben, daß die Zentralgewalt ihre Befugnisse überschreitet. Diese Sicht des amerikanischen Föderalismus hat sich jedoch in den Vereinigten Staaten nicht durchgesetzt ${ }^{65}$. Nach Europa gelangte sie bezeichnenderweise als staatenbündische Konzeption des Bundesstaates, die im Bundesstaat quasi einen Staatenbund mit geringerer Dezentralisation erblickt ${ }^{66}$. Die Folge war einmal, daß man im Entstehungsgrund der Gemeinschaft - völkerrechtlicher Vertrag auf der einen, staatsrechtlicher Akt

62 Nach Sec. 178 gilt Kapitel X der Verfassung nicht für den Kachin-Staat, da diesem bei seiner Gründung aus burmesischem Gebiet die Regionen Bhamo und Myitkyina zugeschlagen wurden, die ihn nunmehr für immer an "Burma proper" binden.

63 Maung Maung, a. a. O., S. 193; rechtspolitisch wird dies damit begründet, daß der frühere Salween District erst nach kriegerischen Auseinandersetzungen als Karen-Staat in die staatliche Ordnung Burmas eingegliedert werden könnte und nicht mehr verlorengehen darf, vgl. U Myint Soe, a. a. O., S. 380 .

64 Calhoun. Discourse on the Constitution and Government of the United States, New York 1850.

$65 \mathrm{Vgl}$. etwa Williams v. Bruffy, Va (1878), 96 US 183: „By reason of the clause (Art. I Section 10 Cl. 1) the confederation formed by Virginia and other States, called the Confederate States of America, could not be recognized as having any legal existence. ${ }^{\alpha}$

$66 \mathrm{Vgl}$. hierzu Brie, Der Bundesstaat, Bd. I, Geschichte der Lehre vom Bundesstaat, Leipzig 1874, S. $192 \mathrm{ff}$. ferner Ebers, Die Lehre vom Staatenbund, Breslau 1910, S. $145 \mathrm{ff}$. In der neue ren Lehre siehe Nawiasky, Der Bundesstaat als Rechtsbegriff, Tübingen 1920, ders. Allgemeine Staatslehre, Bd. 2/II, Zürich, Köln 1956, $\S 46 \mathrm{Nr} .5$ und $\$ 55 \mathrm{Nr} .10$. 
auf der anderen Seite - ein qualitatives Unterschiedsmerkmal zwischen Staatenbund und Bundesstaat suchte ${ }^{67}$, zum anderen, daß man - namentlich in der unter dem Eindruck der Sezession der Südstaaten stehenden amerikanischen Literatur das Sezessionsrecht aus der bundesstaatlichen Verfassungsordnung zu verbannen trachtete ${ }^{68}$. Beide Wege haben sich in Theorie und Verfassungspraxis als falsch erwiesen, da der völker- oder staatsrechtliche Entstehungsgrund der Gemeinschaft oder Verbindung für den Status der Rechtsgemeinschaft ohne weitere Bedeutung ist $^{69}$. Dasselbe gilt bezüglich des Sezzionsrechts.

2. Das Sezessionsrecht einer Rechtsgemeinschaft deutet weder auf eine beibehaltene latente Völkerrechtssubjektivität hin, noch vermittelt es eine solche. Als erster hat wohl Kelsen erkannt, daß der legale Austritt aus einer Gemeinschaft nichts mit der rechtlichen Qualifizierung ihrer Mitglieder $\mathrm{zu}$ tun hat, sondern allein eine Frage des "zeitlichen Geltungsbereichs von Normen und Normenkomplexen“ darstellt; es handelt sich um die Frage des möglichen Inhalts von Rechtsnormen. Im Rahmen ihrer Vertragsfreiheit und Verfassungsautonomie können die Staaten über die Dauer der jeweiligen Verbindung frei befinden. So kann den Einzelstaaten des Staatenbundes durch den konstituierenden völkerrechtlichen Vertrag ein Austritt versagt sein ${ }^{70}$; andererseits kann eine bundesstaatliche Verfassung den Gliedstaaten den Austritt ermöglichen ${ }^{71}$. In aller Regel wird eine wenig intensive Staatenverbindung eher den freien Austritt gestatten, als eine fest zusammengeschmiedete föderalistische Ordnung ${ }^{72}$. Diese rechtssoziologischen Erkenntnisse binden jedoch die konkrete Verfassungsgestaltung nicht, für die auch noch andere Motive ausschlaggebend werden können ${ }^{73}$.

Demnach kann weder aus der völkerrechtlichen Natur einer Staatenverbindung ein Austrittsrecht der Einzelstaaten deduziert werden, noch indiziert umgekehrt das Sezessionsrecht einer Rechtsgemeinschaft deren Völkerrechtssubjektivität ${ }^{74}$. Die

67 Vgl. hierzu Berber, a. a. O., S. $143 \mathrm{f}$. Zur Unhaltbarkeit der in der Staatsrechtslehre des 19. Jahrhunderts entwickelten Differenzierung siehe Verdross, Die Verfassung der Völkergemeinschaft, Berlin 1926, S. 108 ff., und Kunz, Staatenverbindungen, a. a. O., S. $627 \mathrm{ff}$. Da die Staaten, die durch Vertrag sich zu einem Bundesstaat zusammenschließen, mit der Vertragserfüllung als Staaten im Sinne des Völkerrechits untergehen, wird rechtlich das gleiche erreicht wie bei der Dezentralisierung durch Gesetz des Einheitsstaates. Politisch betrachtet, kann die Entstehung des Bundesstaates durch Vertrag Elemente für eine lebendige Fortentwicklung des Föderalismus abgeben, da - wie Lerche (VVdStRL, Heft 21 [1964], S. 99 f.) zutreffend bemerkt - manche Vertragszüge weiterwirken; vgl. hierzu auch Carl Schmitt, Verfassungslehre, Berlin 1954, unveränderter Nachdruck der Aufl. von 1928, S. $65 \mathrm{ff}$. Dies muß jedoch nicht sein; gerade bei der Dekolonialisierung entwickelt der Föderalismus, obgleich auf unitarischer Grundlage entstanden, eher zentrifugale als zentralistische Kräfte.

68 So z. B. Ullmann, Völkerrecht, Tübingen 1909, S. $198 \mathrm{ff}$; Redslob, Théorie de la Société des Nations, Paris 1927, S. 16 f., $25 \mathrm{ff}$. und vor allem die US-amerikanische Staatsrechtslehre, vgl. Friedrich, Nationaler und internationaler Föderalismus in Theorie und Praxis, in: Politische Vierteljahresschrift 1964, Heft 2, S. 181 .

69 Nachweise oben Fn. 67.

70 So war nach Art. I der Bundesakte und Art. V der Wiener Schlußakte der Deutsche Bund ein unauflöslicher Staatenbund; keinem der Mitgliedstaaten stand der Austritt frei. Ebenso sind die im Rahmen des EWG-Vertrages erfolgten Kompetenzübertragungen an die Wirtschaftsgemeinschaft endgültig und unkündbar; vgl. W. Fischer, Das Austrittsrecht aus Staatenverbindungen, Diss. Zürich, 1957, S. 42.

71 So auch Kunz, Staatenverbindungen, a. a. O., S. 672.

72 So Dahm, Völkerrecht, Stuttgart 1958/61, Bd. II, S. 19.

73 Ein Sezessionsrecht kann trotz der von der Verfassung beabsichtigten weitgehenden Integration statuiert werden, um noch außerhalb der Union stehenden Staaten den Entschluß zum Beitritt zu erleichtern, um den Gliedstaaten eine weitere Möglichkeit $\mathrm{zu}$ verschaffen, den Zentralstaat zu gliedstaatenfreundlichem Verhalten $\mathrm{zu}$ veranlassen. Andererseits kann im Staatenbund die Normierung eines Sezessionsverbotes ein angemessenes Mittel sein, den eigenstaatlichen Egoismus in der beabsichtigten Weise zu bekämpfen und für den Bestand der Gemeinschaft günstige psychologische und politische Voraussetzungen zu schaffen; vgl. hierzu insbes. Bindschedler, Rechtsfragen der europäischen Einigung (ein Beitrag zur Lehre von den Staatenverbindungen), Basel 1954, S. $40 \mathrm{ff}$.

74 Diese Ansicht hat sich allerdings noch nicht in Schrifttum und Lehre durchzusetzen vermocht; so betont Dahm, daß die Mitgliedstaaten eines Staatenverbandes Träger der vollen Hoheitsgewalt bleiben, solange sie das Recht haben, sich im Konfliktfalle vom Verband zu lösen (a. a. O., Bd. II, S. 19); nach Mosler ist die Souveränität der Gliedverbände einer höheren Organisation gleichbedeutend mit der Frage nach der Austrittsmöglichkeit (Festschrift für Thoma, Tübingen 1950, S. 153); Fleiner sieht im Kündigungsrecht den Ausdruck der Souveränität der Staaten (Die Kleinstaaten in den Staatenverbindungen des zwanzigsten Jahrhunderts, Zürich 1966, S. 321); auch nach der sowjetischen Lehre ist das Sezessionsrecht die Grundlage der Souveränität der Unionsrepubliken (vgl. Nachweise bei Halajczuk, a. a. O., S. 129). 
innerstaatlichen Rechtsgemeinschaften, denen vom Gesamtverband ein Sezessionsrecht eingeräumt wird, besitzen deshalb keine, etwa den protegierten Staaten vergleichbare Völkerrechtssubjektivität. Nehmen diese Rechtsgemeinschaften was durchaus nicht immer der Fall zu sein braucht ${ }^{75}$ - am zwischenstaatlichen Verkehr teil, so geschieht das nur aufgrund einer speziellen oder allgemeinen Ermächtigung durch das Staatsgrundgesetz, wie sie auch Rechtsgemeinschaften ohne Sezessionsrecht zuteil werden kann. Dies gilt auch für die Unionsrepubliken der UdSSR $^{76}$ und die assoziierten Staaten, für die die Erlangung der Unabhängigkeit nicht ausgeschlossen wird ${ }^{77}$.

3. Ist auch das Sezessionsrecht einer innerstaatlichen Rechtsgemeinschaft für deren Status im zwischenstaatlichen Verkehr zumindest so lange ohne Bedeutung, wie von diesem Recht kein Gebrauch gemacht worden ist, so können doch schon von dem Austrittsrecht als solchem gewisse Wirkungen auf die Beziehungen im Staatenverband ausgehen, die auch für die Dezentralisation der auswärtigen Gewalt wichtig sind. Das Sezessionsrecht einer Teilordnung kann den Gesamtstaat veranlassen, seine Außenpolitik in Übereinstimmung mit den Interessen der Gliedstaaten zu führen, da sich die Rechtsgemeinschaft den sie nachteilhaft betreffenden Folgen eines ohne ihre direkte oder indirekte Mitwirkung abgeschlossenen völkerrechtlichen Vertrages durch legale Sezession entziehen kann. Das Sezessionsrecht wird so zu einem Notwehrrecht der innerstaatlichen Gemeinschaft gegenüber dem Staatenverband oder dem Oberstaat ${ }^{78}$. Die verfassungsmäßige Ordnung wird dadurch gekennzeichnet, daß die „elementare Atmosphäre der Verfassungsschöpfung "79 andauert und zu ständig neuer Rücksichtnahme und Interessenabwägung zwingt.

4. Die Entwicklung in der Verfassungswirklichkeit zeigt, daß die erhöhte Rücksichtnahme auf eine durch ein Sezessionsrecht privilegierte innerstaatliche Rechtsgemeinschaft nicht die einzig mögliche Reaktion der höheren Organisation dar-

75 So nehmen etwa die jugoslawischen Republiken, die burmesischen Staaten und die mit Neuseeland assoziierten Cook-Islands nicht am völkerrechtlichen Verkehr teil. Vgl. Einzelheiten Blumenwitz, Der Schutz innerstaatlicher Rechtsgemeinschaften beim Abschluß völkerrechtlicher Verträge - Ein Beitrag zur Dezentralisierung der auswärtigen Gewalt in den föderalen Staatsordnungen der Gegenwart, München 1971. 76 Die verfassungsmäßige Ordnung in der UdSSR hat nicht zuletzt wegen des den Unionsrepubliken eingeräumten Sezessionsrechtes die Qualifikation, ob Bundesstaat oder Staatenbund, sehr erschwert; vgl. hierzu insbes. Mouskhety, Das Paradox des sowjetischen Bundesstaats, in: Schweizer Monatshefte, 1959, S. 772, und neuerdings Halajczuk, a. a. O., S. $128 \mathrm{ff}$. vgl. oben Fn. 45 a. E. Die Besonderheit des Sezessionsrechts der sowjetischen Unionsrepubliken (zumindest was die ukrainische, weißrussische und die transkaukasische Sowjetrepublik anbelangt) besteht in der Vereinbarung durch völkerrechtlichen Vertrag. Für diesen völkerrechtlichen Vertrag gilt jedoch dasselbe wie für alle einen Bundesstaat begründenden völkerrechtlichen Verträge: nach dem Entstehen des Bundesstaates werden durch diesen völkerrechtlichen Vertrag keine völkerrechtlichen Rechte oder Pflichten vermittelt, da deren Rechtsträger im Gesamtverband aufgegangen sind; wird das Sezessionsrecht in der Ordnung des Gesamtstaates weiterhin als unveräußerliches Recht angesprochen, so handelt es sich eben um eine verfassungsrechtlich geschützte Position. Daß die Unionsrepubliken - wie die Gliedstaaten der durch völkerrechtlichen Vertrag entstandenen Bundesstaaten - in der UdSSR aufgegangen sind und durch diese grundsätzlich unbeschränkt völkerrechtlich mediatisiert werden, ist unbestreitbar und wird durch die durdı das verfassungsändernde Gesetz vom 1. Februar 1944 erfolgte nachträgliche Dezentralisation der auswärtigen Gewalt nur bestätigt; die in der sowjetischen Lehre immer wieder auftauchenden Beteuerungen von der Souveränität der Gliedstaaten sind - ganz abgesehen von der dialektischen Beschränkung und Verformung des Souveränitätsbegriffs politisch gezielte Versuche, die innerstaatliche Rechtsgemeinschaft über den Verlust des Status hinwegzutrösten.

77 Fieldhouse sieht in der Einführung der vollen inneren Unabhängigkeit, die gleichzeitig das Recht enthält, alle noch bestehenden Bande mit dem Mutterland aus eigenem Entschluß zu lösen, ein Kriterium für die Unabhängigkeit (Die Kolonialreiche seit dem 18. Jahrhundert, Fischer, Weltgeschichte, Bd. 25, Frankfurt a. M. und Hamburg 1965, S. 333); Unabhängigkeit bedeutet nach Goodrich-Hambro die Lösung aller politischen Bande mit einem anderen Staat oder zumindest das Recht, dies zu tun (Charter of the United pations. Commentary and Documents, Boston 1946, S. 235). Auch hier wird - meist aus politischen Gründen - ein Minderstatus mit dem Vollstatus identifiziert; zu Recht weist van Panhuys darauf hin, $\mathrm{da} ß$ das Recht, unabhängig zu werden, noch keine Unabhängigkeit bedeutet (The International Aspects of the Reconstruction of the Kingdom of the Netherlands in 1954, a. a. O., S. 17, Anm. 1). Letzterer Auffassung folgt auch die Staatenpraxis; die Anerkennung der mit Sezessionsrecht assoziierten Staaten stand nie zur Diskussion, vgl. Fahrni, a. a. O., S. 55.

78 Das Sezessionsrecht erscheint so als parallele Erscheinung zum Recht auf Auswanderung und Widerstand.

79 Hierzu Lerche, VVdStL, Heft 21 (1964), S. 99. 
stellt. In der Tat hat das Recht zum legalen Austritt nur bei den frei assoziierten Staaten zu einer mehr oder weniger großen Abstimmung der Interessen bei der Führung der auswärtigen Angelegenheiten durch das Mutterland geführt. Im Bereich der bundesstaatlichen Ordnungen hat das Sezessionsrecht weniger eine echte Abstimmung föderalistischer und zentralistischer Tendenzen als seine innere Aushöhlung bewirkt. Es ist bezeichnend, daß in den Staaten, die ihren Gliedstaaten ein Sezessionsrecht gewähren, die bundesstaatliche Ordnung durch ein mehr oder weniger zentralistisch organisiertes Parteisystem überlagert wird, das die volle Entfaltung des Föderalismus verhindert ${ }^{80}$. Dies zeigen die Verhältnisse in der UdSSR sehr deutlich: Die Entscheidung über die Ausübung des Sezessionsrechts liegt beim Obersten Sowjet der Republik; dieses Organ entscheidet als Staatsorgan in eigenen Angelegenheiten unabhängig von den Unionsorganen, seine Mitglieder sind jedoch als Angehörige der unitarisch organisierten KP an die Beschlüsse und Richtlinien des Politbüros der Kommunistischen Partei der UdSSR gebunden. Uber die Sezession wird deshalb politisch in Moskau entschieden ${ }^{81}$; sie erscheint nur möglich, wenn die lokalen Parteiinstanzen der Zentrale den Gehorsam verweigern, was nach der sowjetischen Doktrin aber wiederum Konterrevolution wäre ${ }^{82}$. Vom freien Austrittsrecht der Unionsrepubliken ist damit so gut wie nichts übriggeblieben. Art. 17 der Verfassung der UdSSR ist dadurch aber wie vielfach in der westlichen Literatur vertreten - nicht völlig bedeutungslos; rechtlich ermöglicht er dritten Staaten die Anerkennung und Unterstützung einer Unionsrepublik, die sich von der UdSSR losgesagt hat, ohne sich hierbei in die inneren Angelegenheiten der UdSSR einzumischen ${ }^{83}$. Der Oberste Sowjet der Republik, der den Austritt aus der Union beschließt, handelt zwar konterrevolutionär, was die Partei anbelangt, jedoch legitim, was die Verfassung betrifft; grundsätzlich ist nur letzteres für dritte Staaten entscheidend.

\section{Zusammenfassung}

Das Sezessionsrecht innerstaatlicher Rechtsgemeinschaften ist in den bundesstaatlichen Verfassungen selten (UdSSR, Jugoslawien, Burma); seine Effektivität wird dort meist noch durch zentralistisch organisierte Einheitsparteien stark eingeschränkt. Im Bereich der staatsrechtlichen Assoziationen ist die verfassungsrechtlich garantierte Befugnis, sich vom Gesamtstaat zu lösen, relativ häufig (Cook Islands, Leeward- und Windward-Islands) und erfüllt im Rahmen von Art. 73 b UN-Charta eine spezifische Funktion.

Das Sezessionsrecht ist weder ein allgemein bundesstaatliches noch ein allgemein staatenbündisches Prinzip; es handelt sich vielmehr um die von der Form der Staatenverbindung unabhängige Begrenzung des zeitlichen Geltungsbereichs von Normenkomplexen, wobei allerdings die hohe Integrationsstufe der bundesstaatlichen Ordnung im allgemeinen eine auf unbestimmte Zeit geschlossene Verbindung bedingt. Andererseits kann das Sezessionsrecht ein wirksamer Garant der bundesstaatlichen Ordnung sein und - sofern es nicht seiner Effektivität beraubt wird die Zentrale daran hindern, die Wirkungen der Föderalstruktur im inneren wie im äußeren Bereich einzuschränken.

80 Dies gilt in vieler Hinsicht auch für Burma, nachdem am 2. März 1962 die Regierung U Nu durch einen Revolutionsrat unter dem Vorsitz von General Ne Win ersetzt wurde.

81 Vgl. Halajczuk, a. a. O., S. 152.

82 Vgl. Maurach, a. a. O., S. 106.

83 Vgl. hierzu auch Halajczuk, a. a. O., S. 153, der allerdings davon ausgeht, daß die originäre Völkerrechtssubjektivität der Unionsrepubliken erhalten geblieben ist und in der Ukraine eine nunterworfene, aber nicht annektierte Nation" erblickt. 